Article

\title{
Efficient Conversion of Acetate to 3-Hydroxypropionic Acid by Engineered Escherichia coli
}

\author{
Ji Hoon Lee ${ }^{1,+}$, Sanghak Cha ${ }^{2,+}$, Chae Won Kang ${ }^{2}$, Geon Min Lee ${ }^{2}$, Hyun Gyu Lim ${ }^{2, * \mathbb{C}}$ \\ and Gyoo Yeol Jung 1,2,* \\ 1 School of Interdisciplinary Bioscience and Bioengineering, Pohang University of Science and Technology, \\ 77 Cheongam-Ro, Nam-Gu, Pohang, Gyeongbuk 37673, Korea; dlwlgns21c@postech.ac.kr \\ 2 Department of Chemical Engineering and, Pohang University of Science and Technology, 77 Cheongam-Ro, \\ Nam-Gu, Pohang, Gyeongbuk 37673, Korea; cktkdgkr@postech.ac.kr (S.C.); \\ codnjs6897@postech.ac.kr (C.W.K.); lgm0417@postech.ac.kr (G.M.L.) \\ * Correspondence: hyungyu.lim@postech.ac.kr (H.G.L.); gyjung@postech.ac.kr (G.Y.J.); \\ Tel.: +82-54-279-8335 (H.G.L.); +82-54-279-2391 (G.Y.J.) \\ + These authors contributed equally to this work.
}

Received: 17 October 2018; Accepted: 3 November 2018; Published: 7 November 2018

\begin{abstract}
Acetate, which is an abundant carbon source, is a potential feedstock for microbial processes that produce diverse value-added chemicals. In this study, we produced 3-hydroxypropionic acid (3-HP) from acetate with engineered Escherichia coli. For the efficient conversion of acetate to 3-HP, we initially introduced heterologous mcr (encoding malonyl-CoA reductase) from Chloroflexus aurantiacus. Then, the acetate assimilating pathway and glyoxylate shunt pathway were activated by overexpressing acs (encoding acetyl-CoA synthetase) and deleting iclR (encoding the glyoxylate shunt pathway repressor). Because a key precursor malonyl-CoA is also consumed for fatty acid synthesis, we decreased carbon flux to fatty acid synthesis by adding cerulenin. Subsequently, we found that inhibiting fatty acid synthesis dramatically improved 3-HP production (3.00 g/L of 3-HP from $8.98 \mathrm{~g} / \mathrm{L}$ of acetate). The results indicated that acetate can be used as a promising carbon source for microbial processes and that 3-HP can be produced from acetate with a high yield (44.6\% of the theoretical maximum yield).
\end{abstract}

Keywords: metabolic engineering; synthetic biology; 3-hydroxypropionic acid; microbial production; fatty acid synthesis; acetate

\section{Introduction}

Microbial conversion is a highly promising process for the production of diverse value-added chemicals and as an alternative to petroleum-based processes [1,2]. Specifically, it can utilize a variety of sugars such as glucose, galactose, xylose and glycerol, which are plentiful in nature and readily available as industrial waste, as a feedstock [3-5]. In addition to these sugars, acetate can be used as a carbon source. Acetate is cheap and greatly abundant, as it can be obtained from biomass hydrolysate or from the conversion of various single-carbon gases [6-8]. Therefore, the use of acetate may reduce the cost of feedstock and thereby facilitate the development of more economic processes. In this regard, several recent studies attempted to engineer microorganisms and demonstrated the successful conversion of acetate into value-added chemicals such as itaconic acid, succinic acid and fatty acid [9-11].

3-Hydroxypropionic acid (3-HP) is one of the important platform chemicals that can be produced by microbial fermentation [12,13]. As 3-HP consists of two functional groups (a hydroxyl and carboxylic 
group), it can be easily converted to other chemicals (e.g., acrylic acid, acrylamide, and propiolactone) for which there are huge markets [12]. Due to its production from sugars, several metabolic pathways have been suggested to date $[12,13]$. While the representative route is the coenzyme- $B_{12}$-dependent dehydration of glycerol [14,15], it is only applicable when the feedstock is glycerol. Alternatively, 3-HP can be produced via the reduction of malonyl-CoA using malonyl-CoA reductase (Figure 1) [16-18]. This pathway is suitable for most carbon sources, including acetate, because malonyl-CoA is a universal intermediate in cells $[16,17]$. Additionally, this pathway does not require an expensive cofactor, coenzyme $\mathrm{B}_{12}$, which is a potential hurdle for the economic production of 3-HP $[18,19]$.

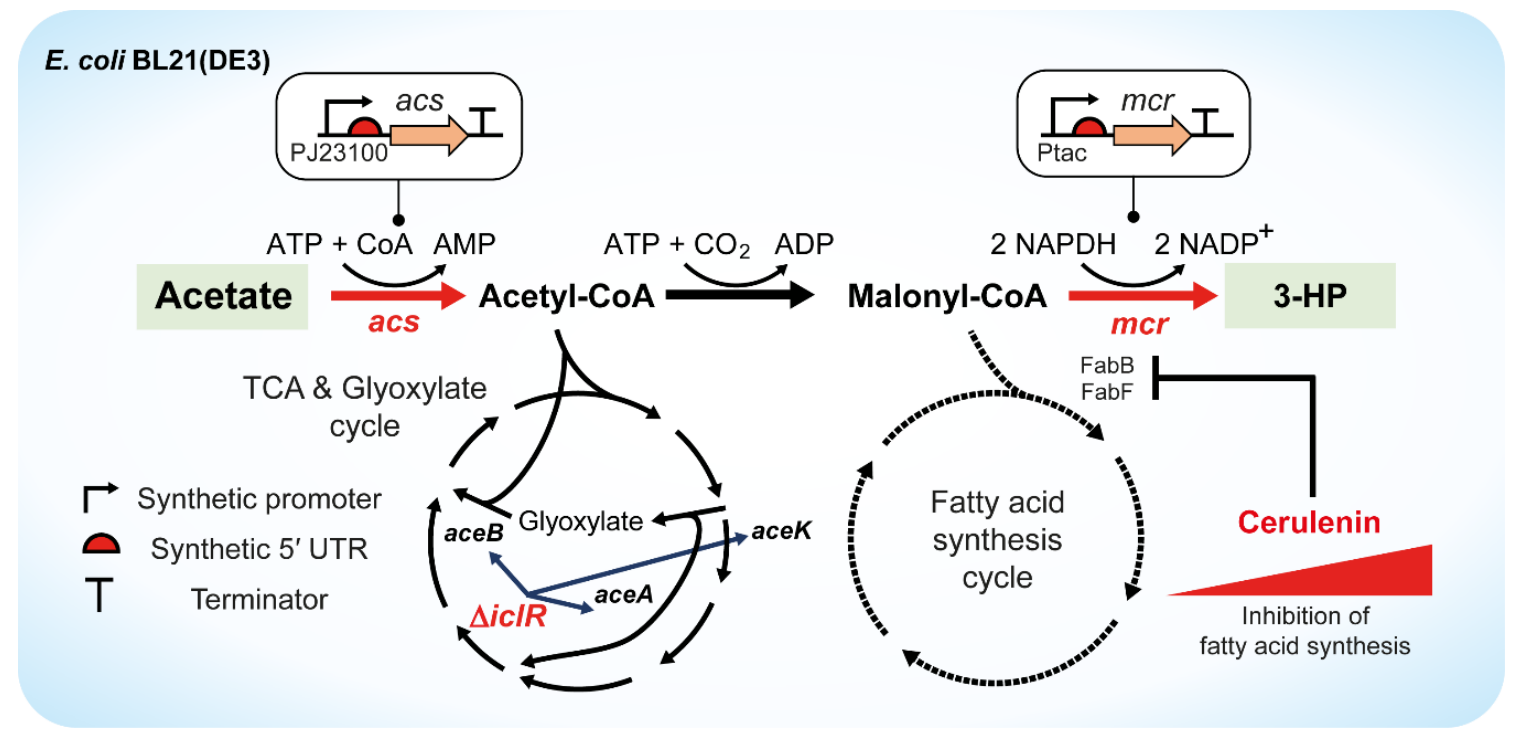

Figure 1. Schematic diagram of a metabolic pathway for the 3-HP production from acetate. 3-HP was synthesized by heterologous overexpression of $\mathrm{mcr}$ (encoding malonyl-CoA reductase from C. aurantiacus). For accelerated acetate assimilation, acs (encoding acetyl-CoA synthetase) was overexpressed and $i c l R$ (encoding glyoxylate shunt pathway repressor) was deleted. Deletion of $i c l R$ upregulates the expression of $a c e A$ (encoding isocitrate lyase), aceB (encoding malate synthase), and aceK (encoding isocitrate dehydrogenase kinase/phosphatase). Phosphorylation of isocitrate dehydrogenase (encoded by $i c d$ ) results in its reduced activity. Different amounts of cerulenin were added to inhibit fatty acids biosynthesis.

To achieve the efficient conversion of acetate to 3-HP, acetate should be rapidly utilized. However, microorganisms slowly utilize acetate as a carbon source and exhibit reduced cell growth $[20,21]$. Therefore, acetate assimilation and biomass formation should be accelerated via genetic engineering [11,22-24]. Furthermore, once acetate is assimilated, malonyl-CoA has to be sufficiently converted to 3-HP. However, the primary use of malonyl-CoA in microorganisms is to synthesize fatty acids, which significantly reduces 3-HP production [25-27]. Thus, acetate consumption for fatty acid synthesis should be reduced to improve 3-HP production.

In this study, we demonstrated the efficient conversion of acetate to 3-HP by engineering a representative microorganism, Escherichia coli. Initially, we constructed a synthetic 3-HP production pathway with maximal expression of heterologous $\mathrm{mcr}$ (encoding malonyl-CoA reductase) from Chloroflexus aurantiacus. To accelerate acetate consumption, we activated both the acetate assimilating pathway and glyoxylate shunt pathway by amplifying acs, which encodes acetyl-CoA synthetase, and deleting $i c l R$, which encodes the transcriptional repressor of the glyoxylate shunt pathway operon. Additionally, to enhance the conversion of malonyl-CoA to 3-HP, carbon flux into a competing pathway (i.e., fatty acid biosynthesis) was inhibited by adding cerulenin at different concentrations. Consequently, we demonstrated that 3-HP could be efficiently produced from acetate using the engineered microbial process. 


\section{Results}

\subsection{Heterologous Expression of mor for 3-HP Production from Acetate}

For 3-HP production, we introduced mcr from C. aurantiacus into the E. coli strain BL21(DE3) (Figure 1). To increase carbon flux toward 3-HP biosynthesis, we expressed mor at a maximum level. Specifically, we developed a synthetic cassette with a strong inducible promoter $\left(\mathrm{P}_{t a c}\right)$ and a synthetic 5' UTR (Table 1) designed using UTR Designer [28] to ensure high transcription and translation levels. Furthermore, we used the pETDuet plasmid, which has a high copy number ( 40 copies per cell), to ensure its overexpression. Additionally, we introduced 3 point mutations (N940V, K1106W, S1114R) known to enhance the activity of malonyl-CoA reductase [16].

Table 1. Synthetic $5^{\prime}$ UTR for gene expression.

\begin{tabular}{ccc}
\hline Gene & $\mathbf{5}^{\prime}$ UTR sequence $\left(\mathbf{5}^{\prime}-\mathbf{3}^{\prime}\right)^{\mathbf{a}}$ & Predicted Expression Level (a.u.) \\
\hline$m c r$ & AACAATTACTAGTAAGGAGAGGAGT & $3,110,669.92$ \\
$a c s$ & AAAATCAGCGCCCAAGGAGTCACCG & $1,074,836.02$ \\
\hline a ${ }^{\prime}$ UTR sequences were designed using UTR Designer [26]. ${ }^{\mathbf{b}}$ This sequence was originally designed in a previous \\
study [9].
\end{tabular}

Following this, we cultivated the HJ1 strain (Table 2), which is BL21(DE3) with the constructed plasmid (pET- $\left.m c r^{*}\right)$, in modified minimal medium. After $48 \mathrm{~h}$ of fermentation, the HJ1 strain consumed $8.55 \mathrm{~g} / \mathrm{L}$ of acetate and produced $95.7 \mathrm{mg} / \mathrm{L}$ of 3-HP (Figure 2). Although we successfully produced 3-HP from acetate with this engineered E. coli strain, the achieved titer was too low $(1.49 \%$ of the theoretical maximum yield). Thus, the strain required further engineering to improve 3-HP production with efficient acetate utilization.

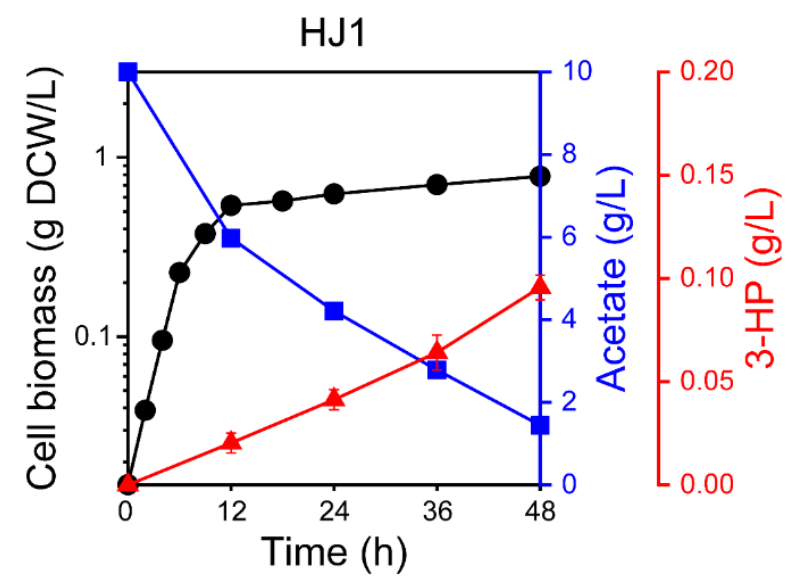

Figure 2. Time-course fermentation profile of the HJ1 strain. The left $y$-axis, right $y$-axis and right $\mathrm{y}$-offset represent the cell biomass ( $\mathrm{g}$ DCW/L), acetate $(\mathrm{g} / \mathrm{L})$ and 3-HP $(\mathrm{g} / \mathrm{L})$, respectively. The $\mathrm{x}$-axis denotes time (h). Symbols: circles, cell biomass; squares, acetate; triangles, 3-HP. The error bars indicate standard deviations for measurements from three independent cultures. One $\mathrm{OD}_{600}$ unit corresponds to $0.31 \mathrm{~g}$ dry cell weight (g DCW/L).

\subsection{Engineering the Acetate Assimilation and Glyoxylate Shunt Pathways}

Compared to that of other sugars, the assimilation rate of acetate in microorganisms is relatively low [8]. Therefore, we investigated the effect of activating the acetate assimilation pathway on 3-HP production. To improve acetate uptake during the entire fermentation period, we expressed acs (encoding acetyl-CoA synthetase) with a synthetic expression cassette consisting of the strong constitutive promoter $\left(\mathrm{P}_{\mathrm{J} 23100}\right)$ and a synthetic $5^{\prime}$ UTR (Table 1$)$. The synthetic expression cassette was inserted into the pACYCDuet plasmid, which has a moderate copy number (10-12 copies/cell), and 
the pACYC-Acs plasmid was introduced into the HJ1 strain, resulting in the HJ2 strain. Compared to the HJ1 strain, the HJ2 strain showed increased acetate consumption (a 1.11-fold increase) and cell biomass (a 1.90-fold increase), indicating that acetate assimilation was successfully expedited by acs overexpression (Figure 3A,B). Furthermore, the improved acetate assimilation in the HJ2 strain led to a 1.75 -fold increase in 3-HP production $(0.17 \mathrm{~g} / \mathrm{L}$, Figure $3 \mathrm{C})$.

(A)

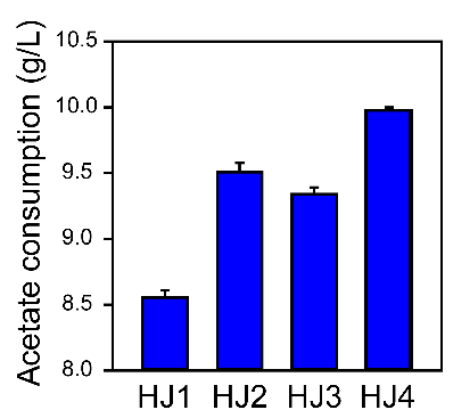

(B)

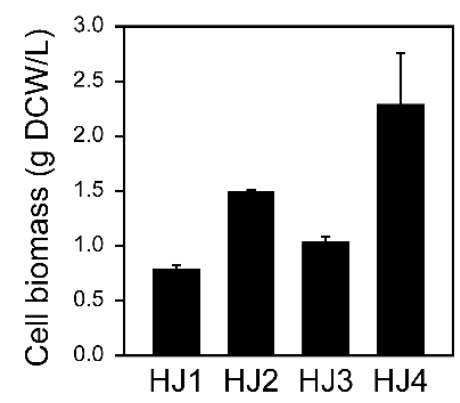

(C)

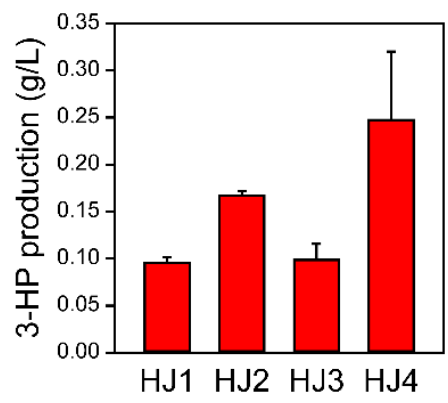

Figure 3. Genetic engineering to improve 3-HP production from acetate. Acetate consumption $(\mathrm{g} / \mathrm{L})$, cell biomass (g DCW/L) and 3-HP (g/L) production of the HJ1-4 strains after $48 \mathrm{~h}$ of fermentation. (A) Acetate consumption (g/L), (B) cell biomass (g DCW/L), and (C) 3-HP production $(\mathrm{g} / \mathrm{L}$ ) of engineered strains were compared. The error bars indicate standard deviations for measurements from three independent cultures.

We then evaluated the effect of activating the glyoxylate shunt pathway. Because the glyoxylate shunt pathway is responsible for a key anaplerotic reaction during acetate utilization, we expected that its activation would facilitate biomass formation and improve acetate consumption. To investigate this effect, we deleted chromosomal iclR, which is known to repress the expression of aceBAK in the glyoxylate shunt pathway $[11,29,30]$, in the HJ1 strain. Similar to the results for the overexpression of acs, the acetate consumption and cell biomass of the resultant $\mathrm{HJ} 3$ strain were enhanced 1.09-fold and 1.31-fold, respectively (Figure 3A,B). These results indicated that iclR deletion successfully enhanced cell biomass synthesis from acetate, which resulted in increased overall acetate consumption.

When the overexpression of acs and deletion of $i c l R$ were combined, the acetate uptake rate (1.16-fold increase) and cell biomass (2.61-fold increase) were further enhanced (HJ4 strain, Figure 3A,B). Moreover, its 3-HP production was synergistically improved 2.54-fold $(0.25 \mathrm{~g} / \mathrm{L})$ compared to that of the HJ1 strain (Figure 3C). Consequently, the combination of acs overexpression and iclR deletion resulted in the most significant improvement in acetate assimilation and 3-HP production. However, despite the improvement, only a small amount of acetate was converted to $3-\mathrm{HP}(3.35 \%$ of the theoretical maximum yield), indicating that further flux control is required for the efficient conversion of acetate to 3-HP.

\subsection{Improved 3-HP Production from Acetate by Inhibiting Fatty Acid Synthesis}

Despite the elevated acetate consumption level, the 3-HP titer was still low, indicating the inefficient conversion of malonyl-CoA due to leakage toward fatty acid synthesis. Therefore, we decided to inhibit fatty acid synthesis to increase the intracellular malonyl-CoA pool for 3-HP production (Figure 1). Bacterial fatty acid synthesis can be inhibited by the addition of cerulenin, which binds to FabB and $\mathrm{FabF}$ and irreversibly inactivates them [31-33]. Thus, we cultivated the HJ4 strain with the addition of different levels of cerulenin $(10,25,50$ and $100 \mu \mathrm{M})$ to gradually reduce carbon flux from malonyl-CoA to fatty acids. As expected, the addition of cerulenin was unfavorable for cell growth (Figure 4A-C). On the other hand, notably, it was highly beneficial for 3-HP production, as the titers and yields were dramatically increased. Specifically, when $50 \mu \mathrm{M}$ of cerulenin was added, the HJ4 strain produced $3.00 \mathrm{~g} / \mathrm{L}$ of $3-\mathrm{HP}$ while consuming $8.98 \mathrm{~g} / \mathrm{L}$ of acetate $(0.30 \mathrm{~g} / \mathrm{g}, 44.6 \%$ of the maximum theoretical yield, Figure 4D). This titer was 12.0-fold higher compared to the 3-HP titer produced by the same 
strain without cerulenin addition. These results indicated that 3-HP production from acetate was successfully improved by inhibiting fatty acid biosynthesis and that flux control around malonyl-CoA was critical for the efficient conversion of acetate to 3-HP.

Table 2. Bacterial strains and plasmids used in this study.

\begin{tabular}{|c|c|c|}
\hline Name & Description & Source \\
\hline \multicolumn{3}{|l|}{ Strains } \\
\hline Mach1-T1 ${ }^{R}$ & E. coli $\mathrm{F}^{-} \varphi 80($ lacZ $) \Delta \mathrm{M} 15 \Delta$ lacX74 hsd $\left.\mathrm{R}_{\left(\mathrm{K}_{\mathrm{K}}\right.}{ }^{-} \mathrm{m}_{\mathrm{K}}^{+}\right) \Delta r e c \mathrm{~A} 1398$ end $\mathrm{A} 1$ ton $\mathrm{A}$ & Invitrogen \\
\hline BL21(DE3) & E. coli $\mathrm{F}^{-}$omp $\mathrm{T}$ gal dcm lon hsdSB $\left(\mathrm{rB}^{-} \mathrm{mB}^{-}\right) \lambda(\mathrm{DE} 3)$ & Invitrogen \\
\hline HJ1 & $\mathrm{BL} 21(\mathrm{DE} 3) / \mathrm{pET}-m \mathrm{cr}^{*}$ & This study \\
\hline HJ2 & BL21(DE3)/pET- $m c r^{*} / \mathrm{pACYC}-a c s$ & This study \\
\hline HJ3 & BL21(DE3) $\Delta i c l R / p E T-m c r^{*}$ & This study \\
\hline $\mathrm{HJ} 4$ & BL21(DE3) $\Delta i c l R / p E T-m c r^{*} / \mathrm{pACYC}-a c s$ & This study \\
\hline \multicolumn{3}{|l|}{ Plasmids } \\
\hline PLB0110 & Source of $m c r$ & [15] \\
\hline pETDuet & Expression vector, ColE1 ori, Amp ${ }^{R}$ & Novagen \\
\hline pACYCDuet & Expression vector, $\mathrm{p} 15 \mathrm{~A}$ ori, $\mathrm{Cm}^{\mathrm{R}}$ & Novagen \\
\hline pKD46 & Red recombinase expression vector, $A m p^{R}$ & [32] \\
\hline pFRT72 $2_{\text {variant }}$ & Source of mutant FRT-kan ${ }^{\mathrm{R}}$-FRT & [33] \\
\hline pCP20 & FLP expression vector, $\mathrm{Amp}^{\mathrm{R}}, \mathrm{Cm}^{\mathrm{R}}$ & {$[32]$} \\
\hline pET-mcr* & $\mathrm{pETDuet} / \mathrm{P}_{\mathrm{tac}}-\mathrm{SynUTR} \mathrm{R}_{m r}-m c r$ N940V, K1106W, S1114R & This study \\
\hline pACYC-acs & pACYCDuet $/ \mathrm{P}_{\mathrm{BBa} \_} \mathrm{J} 23100-\mathrm{SynUTR}_{a c s}-a c s$ & This study \\
\hline
\end{tabular}

(A)

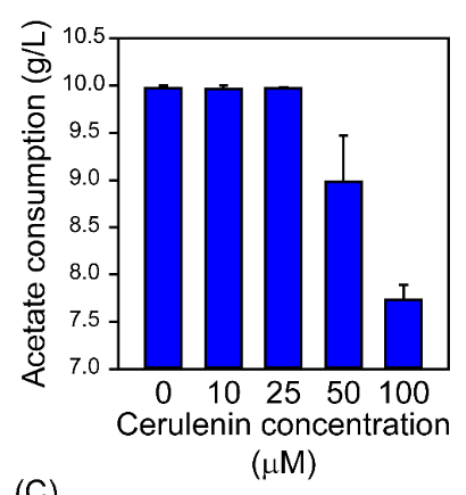

(C)

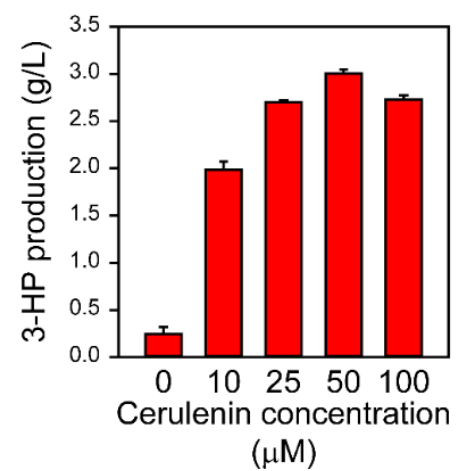

(B)
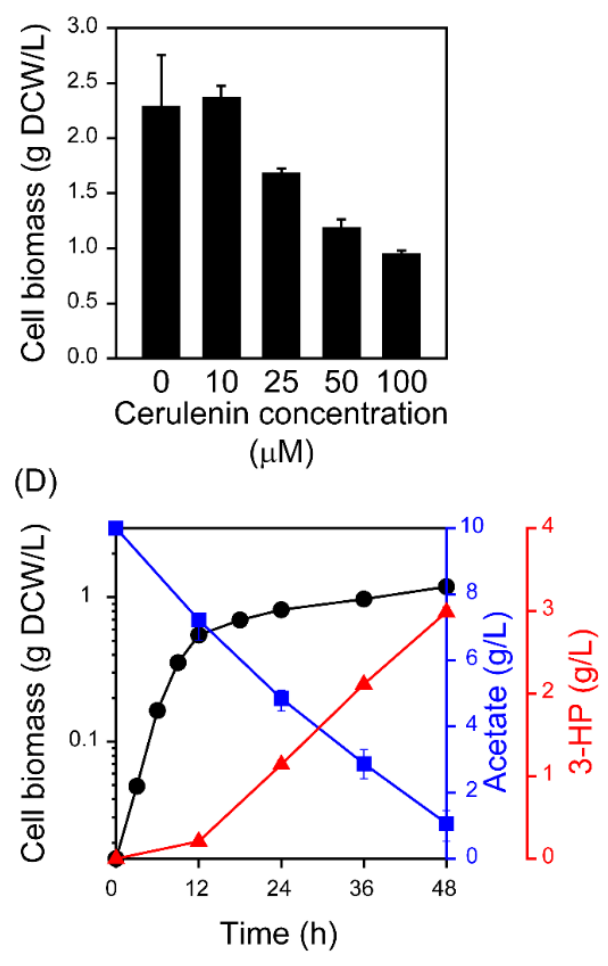

Figure 4. Improved 3-HP production with the addition of cerulenin. (A) Acetate consumption (g/L), (B) cell biomass ( $\mathrm{g} \mathrm{DCW} / \mathrm{L})$ and $(\mathrm{C}) 3-\mathrm{HP}(\mathrm{g} / \mathrm{L})$ production of the $\mathrm{HJ} 4$ strain with different cerulenin concentrations after $48 \mathrm{~h}$ fermentation. (D) Time-course fermentation profile ( $48 \mathrm{~h})$ of the HJ4 strain with $50 \mu \mathrm{M}$ of cerulenin in a modified acetate minimal medium. The left y-axis, right y-axis and right $\mathrm{y}$-offset represent the cell biomass (g DCW/L), acetate $(\mathrm{g} / \mathrm{L})$ and 3-HP $(\mathrm{g} / \mathrm{L})$, respectively. The x-axis denotes time (h). Symbols: circles, cell biomass; squares, acetate; triangles, 3-HP. The error bars indicate standard deviations for measurements from three independent cultures. 


\section{Discussion}

In this study, we developed a microbial process for the conversion of acetate to 3-HP. Initially, we introduced $m c r$ at a maximum expression level to enable 3-HP production by an E. coli strain. In addition, acetate consumption was expedited by engineering the acetate assimilating pathway and glyoxylate shunt pathway. Furthermore, we increased carbon flux to the 3-HP production pathway by inhibiting fatty acid synthesis with the addition of cerulenin. These efforts allowed us to efficiently convert $8.98 \mathrm{~g} / \mathrm{L}$ of acetate to $3.00 \mathrm{~g} / \mathrm{L}$ of 3-HP. This is the first report on producing 3-HP from acetate, and the achieved yield $(0.30 \mathrm{~g} / \mathrm{g}, 44.6 \%$ of the maximum theoretical yield) was superior to the previously reported value $(0.19 \mathrm{~g} / \mathrm{g})$ with glucose utilization [16].

To further improve the 3-HP production in E. coli, it could be more engineered. For example, the activity of heterologous malonyl-CoA reductase from C. aurantiacus could be improved by codon optimization of the mcr coding sequence. A number of previous studies have shown that codon optimization can elevate the activities of heterologous enzymes [34-36]. Thus, codon optimization of $m c r$ would further enhance 3-HP production by expediting the conversion of malonyl-CoA to 3-HP. Furthermore, because production of 3-HP from acetate requires energy and reducing cofactor, their stable supplementation should be achieved by balancing between the TCA cycle and 3-HP synthesis. Therefore, the fine-tuning of flux toward the TCA cycle should be critical for 3-HP production. Moreover, based on the results obtained in this study, reduction of the flux to fatty acid synthesis may enhance the production of diverse malonyl-CoA-derived biochemicals in E. coli.

\section{Materials and Methods}

\subsection{Reagents}

Oligonucleotides, which are listed in Table 1, were synthesized by Cosmogenetech (Seoul, Korea). Plasmid DNA and genomic DNA were purified using Expin ${ }^{\mathrm{TM}}$ Plasmid SV and Expin ${ }^{\mathrm{TM}}$ Cell SV kits (GeneAll Biotechnology, Seoul, Korea). PCR products were purified using Expin ${ }^{\mathrm{TM}}$ Gel SV kits (GeneAll). Restriction enzymes were purchased from New England Biolabs (Ipswich, MA, USA). Cerulenin was purchased from Cayman Chemical (Ann Arbor, MI, USA). 3-HP was obtained from Tokyo Chemical Industry (Tokyo, Japan). Other chemical reagents were purchased from Sigma-Aldrich (St. Louis, MO, USA).

\subsection{Plasmid Cloning and Bacterial Strain Construction}

All bacterial strains and plasmids used in this study are summarized in Table 2. Synthetic $5^{\prime}$ untranslated regions ( $5^{\prime}$ UTRs) were generated by UTR Designer [28] and are listed in Table 3. E. coli Mach1-T1 ${ }^{\mathrm{R}}$ (Invitrogen, Carlsbad, CA, USA) was used as a cloning host. To construct the pET- $m c r^{*}$ plasmid, $m c r$ was initially amplified from the PLB0110 plasmid [17] using the O-mcr-F1, O-mcr-F2, and O-mcr-B primers to attach a strong inducible promoter $\left(\mathrm{P}_{\mathrm{tac}}\right)$ and a synthetic $5^{\prime}$ UTR. Then, the amplified fragment was digested with BamHI and XhoI endonucleases and inserted into the pETDuet plasmid. It should be noted that the coding sequence of $m c r$ was modified from its original sequence via conventional site-directed mutagenesis using the O-N940V-F and O-N940V-B, O-K1106W-F and O-K1106W-B, and O-S1114R-F and O-S1114R-B primer pairs for the introduction of N940V(AAT to GTG), K1106W (AAG to TGG), and S1114R (AGT to CGT) mutations, respectively [16].

To construct the pACYC-acs plasmid, acs was amplified from the genomic DNA of E. coli BL21(DE3) and attached to the BBa_J23100 promoter obtained from the Registry of Standard Biological Parts (http:/ / parts.igem.org) and a synthetic 5' UTR using the O-Acs-F and O-Acs-B primers. The amplified fragment was digested using EcoRI and SacI restriction enzymes and introduced into the pACYCDuet plasmid.

Genome manipulation was conducted using the Lambda-Red recombination method with the pKD46 plasmid [37]. Chromosomal iclR was deleted by inserting a FRT-kan ${ }^{\mathrm{R}}$-FRT fragment that was 
amplified using the R-iclR-F and R-iclR-B primer pair. The integrated kanamycin resistance gene was removed by expression of the flippase from the pCP20 plasmid.

Table 3. Oligonucleotides used in this study.

\begin{tabular}{|c|c|}
\hline Name & Sequence $\left(5^{\prime}-3^{\prime}\right)$ \\
\hline O-mcr-F1 & $\begin{array}{l}\text { GGAATTGTGAGCGGATAACAATTACTAGTAAGGAGAGGAGT } \\
\text { ATGAGCGGAACAGGACGACT }\end{array}$ \\
\hline O-mcr-F2 & $\begin{array}{l}\text { GGATCCTTGACAATTAATCATCGGCTCGTATAATGTGTG } \\
\text { GAATTGTGAGCGGATAACAATT }\end{array}$ \\
\hline O-mcr-B & $\begin{array}{l}\text { CTCGAGTGCGAAAAAACCCCGCCGAAGCGGGG } \\
\text { TTTTTTGCGGCATGCTTACACGGTAATCGCCCGT }\end{array}$ \\
\hline O-N940V-F & TATTACCTTGCCGACCGCAATGTCAGTGGTGAGACATTCC \\
\hline O-N940V-B & GCGGTCGGCAAGGTAATAG \\
\hline O-K1106W-F & ATTTCCGGGTAGCGCGCAAGATTGCCCTGAGTGATGGTG \\
\hline O-K1106W-B & GCGCGCTACCCGGAAATG \\
\hline O-S1114R-F & TGAGTGATGGTGCCAGTCTCGCGCTGGTCACTC \\
\hline O-S1114R-B & AGACTGGCACCATCACTCAGGGC \\
\hline $\mathrm{O}$-acs-F & $\begin{array}{c}\text { GAATTCTTGACGGCTAGCTCAGTCCTAGGTACAGTGCTAGC } \\
\text { AAAATCAGCGCCCAAGGAGTCACCGATGAGCCAAATTCACAAACACA }\end{array}$ \\
\hline O-acs-B & $\begin{array}{l}\text { GAGCTCAAAAAAAACCCCGCCCTGTCAGGGGCGGGG } \\
\text { TTTTTTTTTTTACGATGGCATCGCGATAG }\end{array}$ \\
\hline R-iclR-F & $\begin{array}{l}\text { TGCCACTCAGGTATGATGGGCAGAATATTGCC } \\
\text { TCTGCCCGCCAGAAAAAGGCATGACCGGCGCGATGC }\end{array}$ \\
\hline R-iclR-B & $\begin{array}{c}\text { TAACAATAAAAATGAAAATGATTTCCACGAT } \\
\text { ACAGAAAAAGGAGACTGTCGCTCAGCGGATCTCATGCGC }\end{array}$ \\
\hline C-iclR-F & CAACATTAACTCATCGGATCAG \\
\hline C-iclR-B & TCTATTGCCACTCAGGTATGATGGGC \\
\hline
\end{tabular}

\subsection{Cultivation Methods}

Cells were cultivated in a modified minimal medium consisting of $100 \mathrm{mM}$ phosphate buffer ( $\mathrm{pH} 7.0), 1.0 \mathrm{~g} / \mathrm{L} \mathrm{NaCl}, 1.0 \mathrm{~g} / \mathrm{L} \mathrm{NH}_{4} \mathrm{Cl}, 0.5 \mathrm{~g} / \mathrm{L} \mathrm{MgSO}_{4} \cdot 7 \mathrm{H}_{2} \mathrm{O}$, and $1.0 \mathrm{~g} / \mathrm{L}$ yeast extract. Pre-neutralized $10 \mathrm{~g} / \mathrm{L}$ acetate with $\mathrm{NaOH}$ was used as a carbon source. To initiate a culture, a single colony was inoculated into $3 \mathrm{~mL}$ of the medium in a test-tube. After an overnight incubation, the turbid culture was refreshed by re-inoculating into fresh medium. When the $\mathrm{OD}_{600}$ reached $\sim 1.0$, the refreshed seed was transferred to a $25 \mathrm{~mL}$ medium in a $300 \mathrm{~mL}$ flask until an $\mathrm{OD}_{600}$ of 0.05 was obtained. Genes under the $P_{\text {tac }}$ promoter were expressed by the addition of $0.1 \mathrm{mM}$ IPTG when the $\mathrm{OD}_{600}$ reached 1 . At this time, different amounts of cerulenin were also added to inhibit fatty acid synthesis. The $\mathrm{pH}$ was adjusted by adding $5 \mathrm{M}$ of $\mathrm{HCl}$ with a $12 \mathrm{~h}$ interval during $48 \mathrm{~h}$ of culture. The plasmids were maintained by adding $50 \mu \mathrm{g} / \mathrm{mL}$ ampicillin, $34 \mu \mathrm{g} / \mathrm{mL}$ chloramphenicol, and $50 \mu \mathrm{g} / \mathrm{mL}$ streptomycin. All cell cultures were conducted with three biological replicates.

\subsection{Analytical Methods}

To monitor the cell growth, $\mathrm{OD}_{600}$ was measured using a UV-1700 spectrophotometer (Shimadzu, Kyoto, Japan). Acetate and 3-HP were quantified using an Ultimate 3000 high-performance liquid chromatography (HPLC) system (Dionex, Sunnyvale, CA, USA). To separate the metabolites, Aminex HPX-87H (Bio-Rad Laboratories, Richmond, CA, USA) was used with $5 \mathrm{mM} \mathrm{H}_{2} \mathrm{SO}_{4}$ solution as a mobile phase $(0.6 \mathrm{~mL} / \mathrm{min})$. The temperature of the column oven was set to $14{ }^{\circ} \mathrm{C}$. Refractive index signals were measured using a Shodex RI-101 detector (Shodex, Klokkerfaldet, Denmark). 


\subsection{Calculation of the Theoretical Maximum Yield}

Initially, 1 mol acetate could be converted into 1 mol acetyl-CoA with the generation of 1 mol AMP from $1 \mathrm{~mol}$ ATP via the Acs pathway. The generation of 1 mol AMP was equivalent to the consumption of $2 \mathrm{~mol}$ ATP (Equation (1)). Next, $1 \mathrm{~mol}$ malonyl-CoA was produced from $1 \mathrm{~mol}$ acetyl-CoA with the consumption of an additional $1 \mathrm{~mol}$ ATP. Finally, $1 \mathrm{~mol}$ malonyl-CoA was converted into $1 \mathrm{~mol}$ 3-HP with the consumption of $2 \mathrm{~mol} \mathrm{NADPH}$ (Equation (3)). Therefore, $3 \mathrm{~mol}$ ATP and $2 \mathrm{~mol} \mathrm{NADPH}$ were required to produce 3-HP from acetate (Equation (4)). They could be obtained from the TCA cycle with the oxidation of $1 \mathrm{~mol}$ acetate $(1 \mathrm{~mol} \mathrm{NADH}$ is equivalent to $2.5 \mathrm{~mol} \mathrm{ATP;} 1 \mathrm{~mol} \mathrm{FADH}$ is equivalent to $1.5 \mathrm{~mol}$ ATP; $1 \mathrm{~mol} \mathrm{GTP}$ is equivalent to $1 \mathrm{~mol} \mathrm{ATP} ; 1 \mathrm{~mol} \mathrm{NADH}$ is equivalent to $1 \mathrm{~mol} \mathrm{NADPH}$ (Equations (1), (5) and (6)). Consequently, the production of $1 \mathrm{~mol} 3-\mathrm{HP}$ required $2 \mathrm{~mol}$ acetate (Equation (7), $50 \% \mathrm{~mol} / \mathrm{mol}$ and $0.75 \mathrm{~g} / \mathrm{g}$ ).

$$
\begin{gathered}
\text { Acetate }+2 \mathrm{ATP}+\mathrm{CoA} \rightarrow \text { Acetyl-CoA }+2 \mathrm{ADP}+2 \mathrm{P}_{\mathrm{i}} \\
\text { Acetyl-CoA }+\mathrm{ATP}+\mathrm{CO}_{2} \rightarrow \text { Malonyl-CoA }+\mathrm{ADP}+\mathrm{P}_{\mathrm{i}} \\
\text { Malonyl-CoA }+2 \mathrm{NADPH} \rightarrow 3-\mathrm{HP}+2 \mathrm{NADP}^{+}+\mathrm{CoA} \\
\text { Acetate }+\mathrm{CO}_{2}+3 \mathrm{ATP}+2 \mathrm{NADH} \rightarrow 3-\mathrm{HP}+3 \mathrm{ADP}+3 \mathrm{P}_{\mathrm{i}}+2 \mathrm{NAD}^{+} \\
\text {Acetyl-CoA }+3 \mathrm{NAD}^{+}+\mathrm{FAD}^{+}+\mathrm{GDP}+\mathrm{P}_{\mathrm{i}} \rightarrow 2 \mathrm{CO}_{2}+3 \mathrm{NADH}+\mathrm{FADH}+\mathrm{GTP}+\mathrm{CoA} \\
\text { Acetate }+2 \mathrm{NADP}^{+} \rightarrow 2 \mathrm{CO}_{2}+2 \mathrm{NADPH}+3 \mathrm{ATP} \\
2 \mathrm{Acetate} \rightarrow 3-\mathrm{HP}+\mathrm{CO}_{2}
\end{gathered}
$$

Author Contributions: Conceptualization, J.H.L., S.C., H.G.L., and G.Y.J.; methodology, J.H.L., S.C., H.G.L., and G.Y.J.; software, J.H.L.; validation, J.H.L. and S.C.; formal analysis, J.H.L. and S.C.; investigation, J.H.L., S.C., C.W.K., and G.M.L.; resources, J.H.L., S.C., C.W.K., and G.M.L.; data curation, J.H.L., S.C., C.W.K., and G.M.L.; writing-original draft preparation, J.H.L., S.C., C.W.K., and G.M.L.; writing-review and editing, H.G.L. and G.Y.J.; visualization, J.H.L., S.C., H.G.L., and G.Y.J.; supervision, H.G.L. and G.Y.J.; project administration, G.Y.J.; funding acquisition, G.Y.J.

Funding: This research was supported by the C1 Gas Refinery Program (NRF-2018M3D3A1A01055754) and the Global Research Laboratory Program (NRF-2016K1A1A2912829) funded by the Ministry of Science and ICT. This research was also supported by the Korea Institute of Energy Technology Evaluation and Planning (KETEP) and the Ministry of Trade, Industry \& Energy (MOTIE) of the Republic of Korea (no. 20174030201600).

Conflicts of Interest: The authors declare no conflicts of interest.

\section{References}

1. Kidanu, W.G.; Trang, P.T.; Yoon, H.H. Hydrogen and volatile fatty acids production from marine macroalgae by anaerobic fermentation. Biotechnol. Bioprocess Eng. 2017, 22, 612-619. [CrossRef]

2. Shrestha, B.; Dhakal, D.; Darsandhari, S.; Pandey, R.P.; Pokhrel, A.R.; Jnawali, H.N.; Sohng, J.K. Heterologous production of clavulanic acid intermediates in Streptomyces venezuelae. Biotechnol. Bioprocess Eng. 2017, 22, 359-365. [CrossRef]

3. Luo, X.; Ge, X.; Cui, S.; Li, Y. Value-added processing of crude glycerol into chemicals and polymers. Bioresour. Technol. 2016, 215, 144-154. [CrossRef] [PubMed]

4. Wei, N.; Quarterman, J.; Jin, Y.-S. Marine macroalgae: An untapped resource for producing fuels and chemicals. Trends Biotechnol. 2013, 31, 70-77. [CrossRef] [PubMed]

5. Ha, S.-J.; Galazka, J.M.; Kim, S.R.; Choi, J.-H.; Yang, X.; Seo, J.-H.; Glass, N.L.; Cate, J.H.D.; Jin, Y.-S. Engineered Saccharomyces cerevisiae capable of simultaneous cellobiose and xylose fermentation. Proc. Natl. Acad. Sci. USA 2011, 108, 504-509. [CrossRef] [PubMed]

6. Huang, B.; Yang, H.; Fang, G.; Zhang, X.; Wu, H.; Li, Z.; Ye, Q. Central pathway engineering for enhanced succinate biosynthesis from acetate in Escherichia coli. Biotechnol. Bioeng. 2018, 115, 943-954. [CrossRef] [PubMed] 
7. Novak, K.; Pflügl, S. Towards biobased industry: Acetate as a promising feedstock to enhance the potential of microbial cell factories. FEMS Microbiol. Lett. 2018, 365, fny226. [CrossRef] [PubMed]

8. Lim, H.G.; Lee, J.H.; Noh, M.H.; Jung, G.Y. Rediscovering Acetate Metabolism: Its Potential Sources and Utilization for Biobased Transformation into Value-Added Chemicals. J. Agric. Food Chem. 2018, 66, 3998-4006. [CrossRef] [PubMed]

9. Leone, S.; Sannino, F.; Tutino, M.L.; Parrilli, E.; Picone, D. Acetate: Friend or foe? Efficient production of a sweet protein in Escherichia coli BL21 using acetate as a carbon source. Microb. Cell Fact. 2015, 14, 106. [CrossRef] [PubMed]

10. Yang, J.; Nie, Q. Engineering Escherichia coli to convert acetic acid to $\beta$-caryophyllene. Microb. Cell Fact. 2016, 15, 74. [CrossRef] [PubMed]

11. Noh, M.H.; Lim, H.G.; Woo, S.H.; Song, J.; Jung, G.Y. Production of itaconic acid from acetate by engineering acid-tolerant Escherichia coli W. Biotechnol. Bioeng. 2018, 115, 729-738. [CrossRef] [PubMed]

12. de Fouchécour, F.; Sánchez-Castañeda, A.-K.; Saulou-Bérion, C.; Spinnler, H.É. Process engineering for microbial production of 3-hydroxypropionic acid. Biotechnol. Adv. 2018, 36, 1207-1222. [CrossRef] [PubMed]

13. Kumar, V.; Ashok, S.; Park, S. Recent advances in biological production of 3-hydroxypropionic acid. Biotechnol. Adv. 2013, 31, 945-961. [CrossRef] [PubMed]

14. Seok, J.Y.; Yang, J.; Choi, S.J.; Lim, H.G.; Choi, U.J.; Kim, K.-J.; Park, S.; Yoo, T.H.; Jung, G.Y. Directed evolution of the 3-hydroxypropionic acid production pathway by engineering aldehyde dehydrogenase using a synthetic selection device. Metab. Eng. 2018, 47, 113-120. [CrossRef] [PubMed]

15. Lim, H.G.; Noh, M.H.; Jeong, J.H.; Park, S.; Jung, G.Y. Optimum Rebalancing of the 3-Hydroxypropionic Acid Production Pathway from Glycerol in Escherichia coli. ACS Synth. Biol. 2016, 5, 1247-1255. [CrossRef] [PubMed]

16. Liu, C.; Ding, Y.; Zhang, R.; Liu, H.; Xian, M.; Zhao, G. Functional balance between enzymes in malonyl-CoA pathway for 3-hydroxypropionate biosynthesis. Metab. Eng. 2016, 34, 104-111. [CrossRef] [PubMed]

17. Rathnasingh, C.; Raj, S.M.; Lee, Y.; Catherine, C.; Ashok, S.; Park, S. Production of 3-hydroxypropionic acid via malonyl-CoA pathway using recombinant Escherichia coli strains. J. Biotechnol. 2012, 157, 633-640. [CrossRef] [PubMed]

18. Cheng, Z.; Jiang, J.; Wu, H.; Li, Z.; Ye, Q. Enhanced production of 3-hydroxypropionic acid from glucose via malonyl-CoA pathway by engineered Escherichia coli. Bioresour. Technol. 2016, 200, 897-904. [CrossRef] [PubMed]

19. Liu, C.; Ding, Y.; Xian, M.; Liu, M.; Liu, H.; Ma, Q.; Zhao, G. Malonyl-CoA pathway: A promising route for 3-hydroxypropionate biosynthesis. Crit. Rev. Biotechnol. 2017, 37, 933-941. [CrossRef] [PubMed]

20. Enjalbert, B.; Millard, P.; Dinclaux, M.; Portais, J.-C.; Létisse, F. Acetate fluxes in Escherichia coli are determined by the thermodynamic control of the Pta-AckA pathway. Sci. Rep. 2017, 7, 42135. [CrossRef] [PubMed]

21. Rajaraman, E.; Agarwal, A.; Crigler, J.; Seipelt-Thiemann, R.; Altman, E.; Eiteman, M.A. Transcriptional analysis and adaptive evolution of Escherichia coli strains growing on acetate. Appl. Microbiol. Biotechnol. 2016, 100, 7777-7785. [CrossRef] [PubMed]

22. Chong, H.; Yeow, J.; Wang, I.; Song, H.; Jiang, R. Improving acetate tolerance of Escherichia coli by rewiring its global regulator CAMP receptor protein (CRP). PLoS ONE 2013, 8, e77422. [CrossRef] [PubMed]

23. Fernández-Sandoval, M.T.; Huerta-Beristain, G.; Trujillo-Martinez, B.; Bustos, P.; González, V.; Bolivar, F.; Gosset, G.; Martinez, A. Laboratory metabolic evolution improves acetate tolerance and growth on acetate of ethanologenic Escherichia coli under non-aerated conditions in glucose-mineral medium. Appl. Microbiol. Biotechnol. 2012, 96, 1291-1300. [CrossRef] [PubMed]

24. Kirkpatrick, C.; Maurer, L.M.; Oyelakin, N.E.; Yoncheva, Y.N.; Maurer, R.; Slonczewski, J.L. Acetate and formate stress: Opposite responses in the proteome of Escherichia coli. J. Bacteriol. 2001, 183, 6466-6477. [CrossRef] [PubMed]

25. Liu, T.; Vora, H.; Khosla, C. Quantitative analysis and engineering of fatty acid biosynthesis in E. coli. Metab. Eng. 2010, 12, 378-386. [CrossRef] [PubMed]

26. Yang, Y.; Lin, Y.; Li, L.; Linhardt, R.J.; Yan, Y. Regulating malonyl-CoA metabolism via synthetic antisense RNAs for enhanced biosynthesis of natural products. Metab. Eng. 2015, 29, 217-226. [CrossRef] [PubMed]

27. Zha, W.; Rubin-Pitel, S.B.; Shao, Z.; Zhao, H. Improving cellular malonyl-CoA level in Escherichia coli via metabolic engineering. Metab. Eng. 2009, 11, 192-198. [CrossRef] [PubMed] 
28. Seo, S.W.; Yang, J.-S.; Kim, I.; Yang, J.; Min, B.E.; Kim, S.; Jung, G.Y. Predictive design of mRNA translation initiation region to control prokaryotic translation efficiency. Metab. Eng. 2013, 15, 67-74. [CrossRef] [PubMed]

29. Noh, M.H.; Lim, H.G.; Park, S.; Seo, S.W.; Jung, G.Y. Precise flux redistribution to glyoxylate cycle for 5-aminolevulinic acid production in Escherichia coli. Metab. Eng. 2017, 43, 1-8. [CrossRef] [PubMed]

30. Holms, W.H.; Bennett, P.M. Regulation of isocitrate dehydrogenase activity in Escherichia coli on adaptation to acetate. J. Gen. Microbiol. 1971, 65, 57-68. [CrossRef] [PubMed]

31. Moche, M.; Schneider, G.; Edwards, P.; Dehesh, K.; Lindqvist, Y. Structure of the complex between the antibiotic cerulenin and its target, beta-ketoacyl-acyl carrier protein synthase. J. Biol. Chem. 1999, 274, 6031-6034. [CrossRef] [PubMed]

32. Price, A.C.; Choi, K.H.; Heath, R.J.; Li, Z.; White, S.W.; Rock, C.O. Inhibition of beta-ketoacyl-acyl carrier protein synthases by thiolactomycin and cerulenin. Structure and mechanism. J. Biol. Chem. 2001, 276, 6551-6559. [CrossRef] [PubMed]

33. Rogers, J.K.; Church, G.M. Genetically encoded sensors enable real-time observation of metabolite production. Proc. Natl. Acad. Sci. USA 2016, 113, 2388-2393. [CrossRef] [PubMed]

34. Menzella, H.G. Comparison of two codon optimization strategies to enhance recombinant protein production in Escherichia coli. Microb. Cell Fact. 2011, 10, 15. [CrossRef] [PubMed]

35. Anthony, L.C.; Nowroozi, F.; Kwon, G.; Newman, J.D.; Keasling, J.D. Optimization of the mevalonate-based isoprenoid biosynthetic pathway in Escherichia coli for production of the anti-malarial drug precursor amorpha-4,11-diene. Metab. Eng. 2009, 11, 13-19. [CrossRef] [PubMed]

36. Yim, H.; Haselbeck, R.; Niu, W.; Pujol-Baxley, C.; Burgard, A.; Boldt, J.; Khandurina, J.; Trawick, J.D.; Osterhout, R.E.; Stephen, R.; et al. Metabolic engineering of Escherichia coli for direct production of 1,4-butanediol. Nat. Chem. Biol. 2011, 7, 445-452. [CrossRef] [PubMed]

37. Datsenko, K.A.; Wanner, B.L. One-step inactivation of chromosomal genes in Escherichia coli K-12 using PCR products. Proc. Natl. Acad. Sci. USA 2000, 97, 6640-6645. [CrossRef] [PubMed]

(C) 2018 by the authors. Licensee MDPI, Basel, Switzerland. This article is an open access article distributed under the terms and conditions of the Creative Commons Attribution (CC BY) license (http:/ / creativecommons.org/licenses/by/4.0/). 